\title{
Fluoxetine and Selegiline - Lack of Significant Interaction
}

\author{
C.H. Waters
}

\begin{abstract}
The use of the combination of fluoxetine, an anti-depressant serotonin uptake inhibitor, and selegiline, a monoamine oxidase -B inhibitor, was reviewed in a large population of patients with Parkinson's disease. All records were reviewed from a Parkinson's disease clinic to determine how many patients were treated simultaneously with selegiline and fluoxetine. Patient characteristics, duration and dose of treatment, side effects and reasons for discontinuation were noted. Twenty-three patients received both medications at the same time. No additional side effects were noted with the combination therapy that had not already been reported with each medication alone. No serious side effects were found. In this clinic population, fluoxetine and selegiline were used in combination without major side effects, but further observation is warranted.
\end{abstract}

\begin{abstract}
Résumé: Fluoxétine et sélégiline - absence d'interaction significative. Nous avons revu l'utilisation combinée de la fluoxétine, un anti-dépresseur inhibant la captation de la sérotonine, et de la sélégiline, un inhibiteur de la (MAO)-B, dans une grande population de patients atteints de la maladie de Parkinson. Tous les dossiers d'une clinique de Parkinson ont été revisés pour déterminer combien de patients avaient été traités simultanément par la sélégiline et la fluoxétine. Les caractéristiques des patients, la durée du traitement et la dose, les effets secondaires et les raisons de cessation du traitement ont été relevés. Vingt-trois patients ont reçu les deux médicaments en même temps. Aucun effet secondaire, qui n'avait pas été rapporté avec chacun des médicaments administré en monothérapie, n'a été noté avec la thérapie combinée. Aucun effet secondaire grave n'a été rapporté. Dans la population de cette clinique, la fluoxétine et la sélégiline ont été utilisées en combinaison, sans effet secondaire majeur. Cependant d'autres observations sont requises pour certifier cette absence d'interaction significative.
\end{abstract}

Can. J. Neurol. Sci. 1994; 21: 259-261

Fluoxetine and selegiline are two recently released medications. The anti-depressant fluoxetine is a serotonin uptake inhibitor. ${ }^{\prime}$ Selegiline, used predominantly for enhancing the effects of levodopa in Parkinson's disease (PD), is a monoamine oxidase (MAO)-B inhibitor, ${ }^{2}$ when used in the recommended dose of 10 $\mathrm{mg}$ per day. If this dose is exceeded, it is no longer a selective MAO-B inhibitor. ${ }^{3}$ As serotonin is metabolized by MAO-A, ${ }^{4}$ blocking this enzyme enhances serotonin's action. An interaction between nonspecific MAO inhibitors and fluoxetine can produce a "serotonin syndrome" with tremor, agitation, restlessness, confusion, hypomania, hypertension and diarrhea. ${ }^{5}$ The risk varies with the type of MAO inhibitor, ${ }^{6}$ and in some instances the two types of medication can be used in combination quite safely. ${ }^{7}$ The current manufacturer's recommendation is that fluoxetine (Dista Products) should not be taken with any MAO inhibitor. Although there is little convincing evidence that the combination of fluoxetine-selegiline results in adverse effects, three recent publications suggest a possible interaction between these medications. ${ }^{8-10}$ In the first report, the combination produced mania in one patient and hypertension in another. ${ }^{8}$ In another case report, ataxia was felt to be due to an interaction between the two medications. ${ }^{9}$ In a third report, severe hypertension was produced with associated elevation in plasma and urinary catecholamines. ${ }^{10}$ These reversed within two days of stopping both drugs. Because there is a significant amount of depression in patients with $\mathrm{PD}, 1$ probably due to reduced serotonin, ${ }^{12}$ it would be helpful to know if these two medications can be used together safely. In a large universitybased Parkinson's clinic we were able to review the effects of these combined drugs.

\section{MethodS}

Five hundred and ninety charts were reviewed which represented all the currently active patients with parkinsonism in this movement disorders clinic. All patients had parkinsonism with at least two of the following criteria: rest tremor, rigidity, bradykinesia and loss of postural reflexes. All patients met the DSM III (R) criteria for depression. The following information

From the Division of Movement Disorders, Department of Neurology, University of Southern California, Los Angeles, Califomia.

RECEIVED DECEMBER 7, 1993. ACCEPTED IN FINAL FORM FEBRUARY 25, 1994

Reprint requests to: Cheryl H. Waters, M.D., Department of Neurology, University of Southem California, 1510 San Pablo Street, Suite 615. Los Angeles, Califomia, USA 90033 
was obtained: patient age, sex, years of PD, daily dose of levodopa, use of other antiparkinsonian medications, dates of use of selegiline, dates of use of fluoxetine, reasons for discontinuation of either or both. Response to medication was drawn from the clinic records and not from any formal rating scale.

Patient's age, duration of disease and length of use of medications were calculated from the date that the data was collected, rather than the date that the patient was first or last seen in clinic.

\section{Results}

Twenty-three patients were found to have been treated with fluoxetine and selegiline simultaneously. The mean age of the patients was 64.6 (range $43-80$ years). There were ten females and 13 males. The mean duration of illness was 7.35 years (range 1-20). The mean dose of fluoxetine was $24.56 \mathrm{mg}$ (range $5-40 \mathrm{mg}$ ). The mean dose of selegiline was $8.58 \mathrm{mg}$ (range 5-10 $\mathrm{mg}$ ). Six patients continue to use both medications without difficulty. Eight patients used both medications without difficulty for an average duration of 17.3 months. Two of these eight stopped, because it was felt that their depression was better. Those two received fluoxetine and selegiline in combination for one and 11 months. Reasons for stopping drug are outlined in Table 1. Five patients stopped both medications, for the following reasons. One stopped because of lack of benefit. Four others had their medications discontinued because of worsening confusion or hallucinations associated with underlying dementias

Table 1. Characteristics of patients who used both fluoxetine and selegiline.

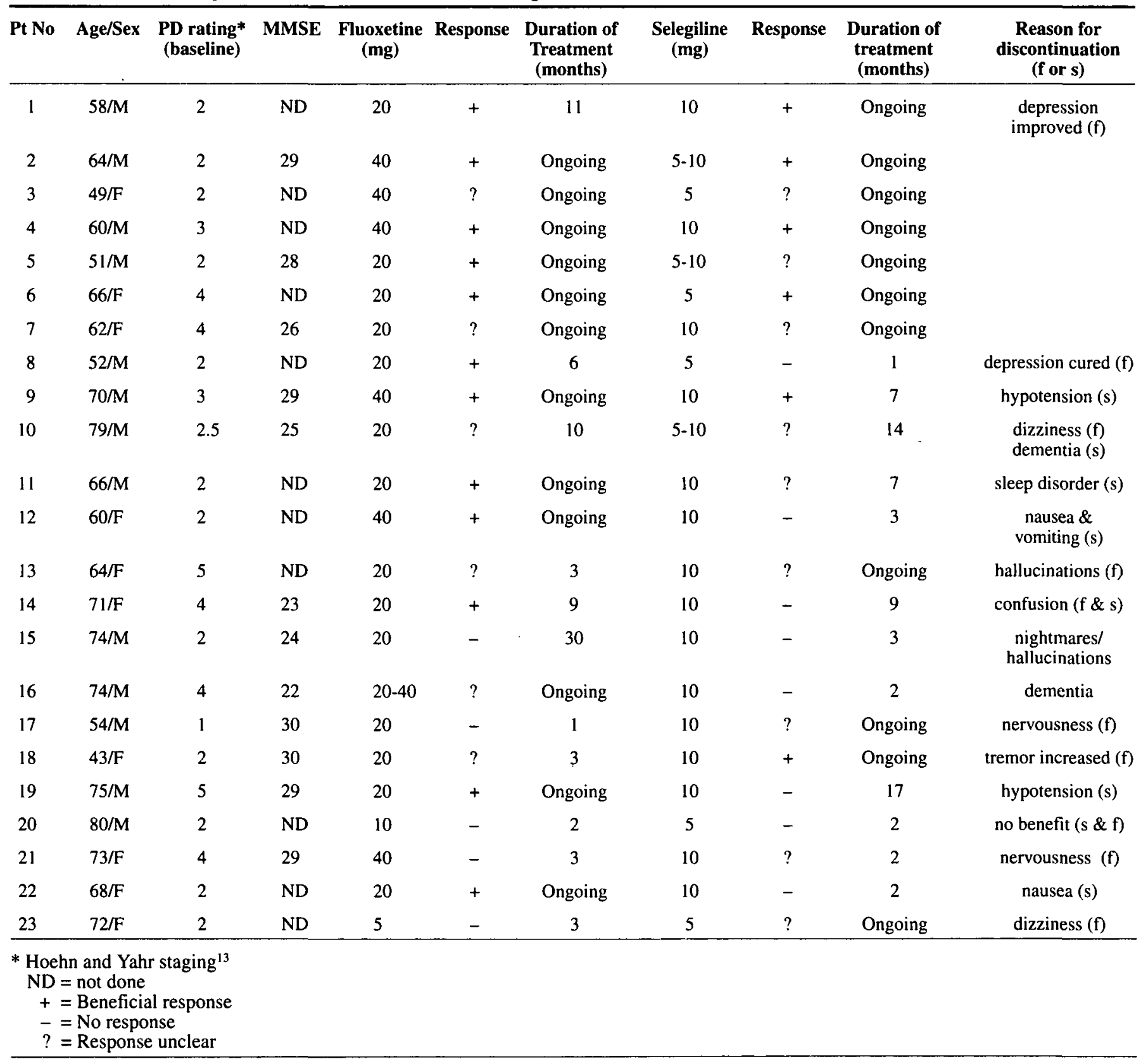


(patients 10,14, 15, 16). In all cases, the mini-mental status examination ${ }^{14}$ score was impaired even before the start of these medications. As both medications were stopped simultaneously in all but one case, it is not possible to determine which of the medications were responsible.

Fluoxetine alone was stopped by seven patients. In two cases this drug was stopped because the underlying depression disappeared. In two cases, fluoxetine produced dizziness and in two other cases nervousness (perceived as anxiety). One patient tried fluoxetine on two occasions, once without selegiline and once with selegiline. On both tries, parkinsonian tremor was worsened. Thus, the combination cannot be implicated.

Selegiline alone was stopped by five patients. Postural hypotension was the reason for discontinuation in two cases, dementia in one (mental status score 25), nausea in one and sleep disturbance in one. In no instance was there a report of a blood pressure change. With the exception of worsening parkinsonian tremor by fluoxetine, no other movement disorder was documented.

\section{Discussion}

The combined use of fluoxetine and selegiline was reviewed in a large movement disorder clinic. This study addressed side effects. We made no formal attempt to determine efficacy of either medication. In 23 patients these two medications combined did not produce the feared "serotonin syndrome". The reasons for discontinuation of medication were those that have been described with either medication alone. Dizziness is commonly described with fluoxetine ${ }^{15}$ and nausea is reported with selegiline, especially when it is added to levodopa. ${ }^{16}$

In one patient, fluoxetine worsened parkinsonian tremor. This has been described in two other reports, ${ }^{17,18}$ and the symptoms resolved after the drug was stopped. Although this could be of some concern in Parkinson's disease, further observation is necessary before restricting this medication in this population.

Confusion was described as part of the syndrome of the combination fluoxetine-MAOI. ${ }^{5}$ It is assumed that this can be attributed to the medications and not an underlying dementia, as there was no mention of a pre-existing problem in that patient population. In our population, an underlying dementia existed in some patients and was documented with abnormal mini-mental status examination ${ }^{14}$ scores. In four patients both fluoxetine and selegiline were discontinued because of worsening confusion and in one case selegiline was stopped for this reason. Although this number appears large (5/23), it reflects the tertiary nature of our referral population with frequently complicated cases.

The dose of fluoxetine used in this population was much lower than those described in one previous report of fluoxetineMAOI, ${ }^{5}$ but the same as that found in another description with a nonspecific MAOI. ${ }^{6}$ It was similar to the doses described in the three reports of a possible fluoxetine-selegiline interaction. ${ }^{8-10}$ A limitation of this retrospective study is the absence of plasma levels of fluoxetine or its metabolite, norfluoxetine. Thus true pharmacokinetic interaction cannot be ruled in or out. It has been proposed that fluoxetine inhibits the demethylation of selegiline and thus prolongs its action. ${ }^{9}$ This may lead to accumulation of selegiline, higher levels and potentially loss of MAO-B specificity.

Depression is common in $\mathrm{PD}^{11}$ and it has been postulated that it is due to a deficiency of serotonin. ${ }^{12}$ Therefore serotonin uptake inhibitors are felt to be appropriate in this setting. There have been studies involving other antidepressants in PD, ${ }^{19}$ but none with fluoxetine or other medications of the same category. Our own practice is to use fluoxetine in the apathetic depressive as it provides stimulation as well as antidepressant effect.

The combination of low dose fluoxetine and selegiline has been quite safe in our patients with parkinsonism who are also depressed. These results cannot be generalized to larger doses of selegiline and in view of previously reported adverse effect, further study is warranted.

\section{REFERENCES}

1. Wong DT, Bymaster FP, Reid LR, et al. Fluoxetine and two other serotonin uptake inhibitors without affinity for neuronal receptors. Biochem Pharmacol 1983; 32: 1287-1293.

2. Knoll J: The possible mechanisms of action of (-) deprenyl in Parkinson's disease. J Neural Transm 1978; 43: 177-198.

3. Schulz R, Antonin KH, Hoffmann E, et al. Tyramine kinetic and pressor sensitivity during monoamine oxidase inhibition by selegiline. Clin Pharmacol Ther 1989; 46: 528-536.

4. Yang H-Y, Neff NH. The monoamine oxidases of brain: selective inhibition with drugs and the consequences for the metabolism of the biogenic amines. J Pharmacol Exp Ther 1974; 189: 733740.

5. Feighner JP, Boyer WF, Tyler DL, Neborsky RJ. Adverse consequences of fluoxetine-MAOI combination therapy. J Clin Psychiatry 1990; 51: 222-225.

6. Sternbach $\mathrm{H}$. Danger of MAOI therapy after fluoxetine withdrawal. Lancet 1988; 2 : 850-851.

7. Peterson GN. Strategies for fluoxetine-MAOI combination therapy. J Clin Psychiatry 1991; 52: 87

8. Suchowersky $O$, deVries J. Possible interactions between deprenyl and prozac. Can J Neurol Sci 1990; 17: 352-353.

9. Hughes PL, Follender AB. Potential fluoxetine-selegiline interaction. Ann Pharmacotherapy 1992; 26: 1300.

10. Montastruc JL, Chamontin B, Senard JM, et al. Pseudophaechromocytoma in parkinsonian patient treated with fluoxetine plus selegiline. Lancet 1993; 341: 555.

11. Mayeux R, Stern Y, Cote L, Williams JBW. Altered serotonin metabolism in depressed patients with Parkinson's disease. Neurology 1984; 34: 642-646.

12. McCance-Katz, Marek KL, Price LH, Serotonergic dysfunction in depression associated with Parkinson's disease. Neurology 1992: 42: 1813-1814.

13. Hoehn MM, Yahr MD. Parkinsonism: onset, progression and mortality. Neurology $1967 ; 17: 427-442$.

14. Folstein MF, Folstein SE, McHugh PR. "Mini-Mental Status." A practical method for grading the cognitive state of patients for the physician. J Psychiatr Res 1975; 12: 189-198.

15. Beasley CM, Bosomworth JC, Wernicke JF. Fluoxetine relationships among dose, response, adverse events, and plasma concentrations in the treatment of depression. Psychopharmacol Bull 1990; 26: 18-24.

16. Waters CH. Side effects of selegiline. J Ger Psych Neurol 1992; 1: 31-34.

17. Bouchard RH, Pourcher E, Vincent P. Fluoxetine and extrapyramidal side effects. Am J Psychiatry 1989; 146: 1352-1353.

18. Jansen Steur ENH. Increase of Parkinson disability after fluoxetine medication. Neurology 1993; 43: 211-212.

19. Cummings JL. Depression and Parkinson's Disease: a review. Am J Psychiatry 1992; 149: 443-454. 